\title{
Downward continuation and tilt derivative of magnetic data for delineation of concealed coal fire in East Basuria Colliery, Jharia coal field, India
}

\author{
S K Pal ${ }^{*}$, Jitendra Vaish, Sahadev Kumar, Piyush Priyam, \\ ABHAY Kumar Bharti and RaJWARdHAN Kumar \\ Department of Applied Geophysics, Indian Institute of Technology (Indian School of Mines), \\ Dhanbad 826004 , India. \\ *Corresponding author.e-mail: sanjitism@gmail.com
}

MS received 30 March 2016; revised 4 November 2016; accepted 6 February 2017; published online 12 June 2017

The present study deals with the characterization of subsurface coal fires of East Basuria colliery in Jharia coal field, India using tilt derivative and downward continuation of magnetic data. Magnetic data processing methods such as diurnal correction, noise removal, reduction to pole, tilt derivative and downward continuation have been used to process the data and for the interpretation of results on the basis of magnetic properties of overlying materials which change with the temperature variation above or below the Curie temperature. Most of the magnetic anomalies are associated with coal fire and non-coal fire regions which are correlated with tilt-derivative anomaly and corresponding downward-continued anomaly at different depths. The subsequent surface and subsurface characteristics are explained with good agreement. Approximate source depth of principal anomaly inferred from tilt derivatives method are corroborated with multi-seam occurrences, mine working levels and surface manifestation which are also correlated well with 3D model of downward continued anomaly distribution.

Keywords. Downward continuation; tilt derivative; magnetic data; coal fire mapping; Jharia coal field; India.

\section{Introduction}

Underground coal fires result in loss of the national economy, pose a threat to the environment, ecology and human health living in their proximities. Coal fires also result in emission of greenhouse gases, toxic gases and vegetation deterioration. The mapping and understanding of hidden subsurface coal fire are challenging tasks. Underground coal fires are severe problems in most of the coal producing countries, viz., China, India, USA, South Africa (Stracher and Taylor 2004; Zhang et al. 2004; Mishra et al. 2011; Revil et al. 2013; Revil and Jardani 2013; Bharti et al. 2014, 2016a, b; Bhattacharya and Shalivahan 2016; Singh et al. 2015; Srivardhan et al. 2016), Australia, Russia, Poland and Indonesia (Ide et al. 2011; Ide and Orr 2011). Generally, satellite remote sensing is the most widely utilized technique for temperature mapping (Majumdar et al. 2012) detection of coal fire regions on the basis of surface temperature anomalies over coal fires affected areas (Prakash et al. 1995, 1997; Prakash and Gupta 1998, 1999; Kuenzer and Stracher 2011; Mishra et al. 2011). The thermal image generated using satellite remote sensing is hardly capable for detection of deeper 
thermal anomalies which may misguide in mapping of subsurface combustion regions (Zhang 1998).

With the advancement of technology, a number of researchers (Hooper 1987; Schaumann et al. 2008; Ide et al. 2011; Vaish and Pal 2013, 2015a, 2016; Shao et al. 2014; Kumar et al. 2015) have used magnetic method for underground coal fire characterization. Generally, magnetic properties of the rocks changing with the temperature variation above or below the Curie temperature is the basis of underground coal fire mapping. The heat produced by burning of coal increases the temperature beyond Curie temperature which results in loss of natural magnetism in nearby areas. Small regions within the crystal structure reorient themselves during cooling by aligning themselves more or less in the direction of the ambient magnetic field. The remnant magnetism may be several times greater in magnitude than the natural magnetism (Shao et al. 2014). The minerals which are formed and their respective magnetic strengths depend on the temperatures and the amount of oxygen available (Hooper 1987; Ide et al. 2011).

In India, coal fires have been studied by various researchers (Prakash and Gupta 1998, 1999; Ghose and Majee 2000; Michalski 2004; Tripathi 2005; Agarwal et al. 2006; Chatterjee 2006; Gangopadhyay 2006; Chatterjee et al. 2007; Singh et al. 2007) by mainly using satellite remote sensing methods on the basis of ambient surface temperature variation. Hitherto in India, only a few studies for coal fire investigation have been carried out in recent years using magnetometer data (Vaish and Pal 2013, 2015a, 2016; Kumar et al. 2015; Pal et al. 2016a). In recent years, potential field data have been effectively used by means of different derivative techniques for various geological investigations (Pal and Majumdar 2015; Narayan et al. 2016; Pal et al. 2016b, c). Present study deals with the delineation of subsurface coal fires of East Basuria Colliery in Jharia coal field, India using tilt derivative and downward continuation techniques of magnetic data.

\section{Study area}

The present study covers an area of $\sim 0.25 \mathrm{~km}^{2}$, lying within the geographical coordinates $23^{\circ} 47^{\prime}$ $34^{\prime \prime}-23^{\circ} 47^{\prime} 53^{\prime \prime} \mathrm{N}$ latitudes and $86^{\circ} 21^{\prime} 59^{\prime \prime}-86^{\circ} 22^{\prime}$ $16^{\prime \prime} \mathrm{E}$ longitudes. Generally, coal seams occur in the Barakar Formation of Lower Gondwana group of rocks of the Early Permian period. Barakar Formation mostly consists of sandstone of different grain size, intercalation of sandstone and shale, grey and carbonaceous shale and coal seams (Vaish and Pal 2015b; Das et al. 2017). The natural topography is harshly affected due to old mining actions, severe underground coal fire activities, land subsidence and overburden dumping. The overburden materials have been dumped over coal fire affected regions to prevent and combat against further exaggeration of coal fire in the surroundings. Initially, the coal fire over East Basuria colliery was observed in V/VI seam quarry in 1976. Afterwards, intense fire was noticed in $\mathrm{V} / \mathrm{VI}$ coal seam at three different galleries in 1995. Water ponds were constructed over the fire affected area in 1996. However, by that time the fire had spread up to VIII and VIIIA seams and resulted in parallel cracking, subsidence, potholing, etc. Keeping V/VI seam as a base, an endeavour against eastward advancement of coal fire was made by cutting a trench during 1997-1998. This effort also showed fruitless because the fire spread through the trench during trenching (Bharat Coking Coal 2003; CMPDI 2003; Coal International 2003; World Bank Group 2003; Pal et al. 2016a). Location map of the East Basuria Colliery, Jharia Coal Field, India along with generalized geological map of Jharia Coal field (figure 1a) and underground mine workings plan (figure 1b) are shown in figure 1. Borehole lithologs of SBJ-56, SBJ-6 and SBJ-4, showing coal seams and shaly coal seams at different depth levels are shown in figure 2 (BCCL 2009). The locations of borehole are shown in figure 1. The major coal bearing seams are VIII, V/VI, IV, III and II with average thickness of $7.2,9.45,9.57,3.66,10.57 \mathrm{~m}$, respectively. L-series of seams are local seam. L-series of seams are thin and not suitable for mining but have the potential for spreading of coal seam fire. The coal seams have varying slope of about $6.7^{\circ}$ $11.3^{\circ}$, with dip direction $\mathrm{NE} 05^{\circ} \mathrm{SW}$ to $\mathrm{NE} 15^{\circ} \mathrm{SW}$ (Singh et al. 2004). Characteristics of coal seams over the East Basuria colliery are described in table 1. Different coal seams with varying slope and dip direction may support the occurrences of coal-seam-fire at different depths and locations which may lead to complex nature of fire propagation.

\section{Methodology}

Total magnetic field intensity with resolution of $0.01 \mathrm{nT}$ have been measured using GSM19T 


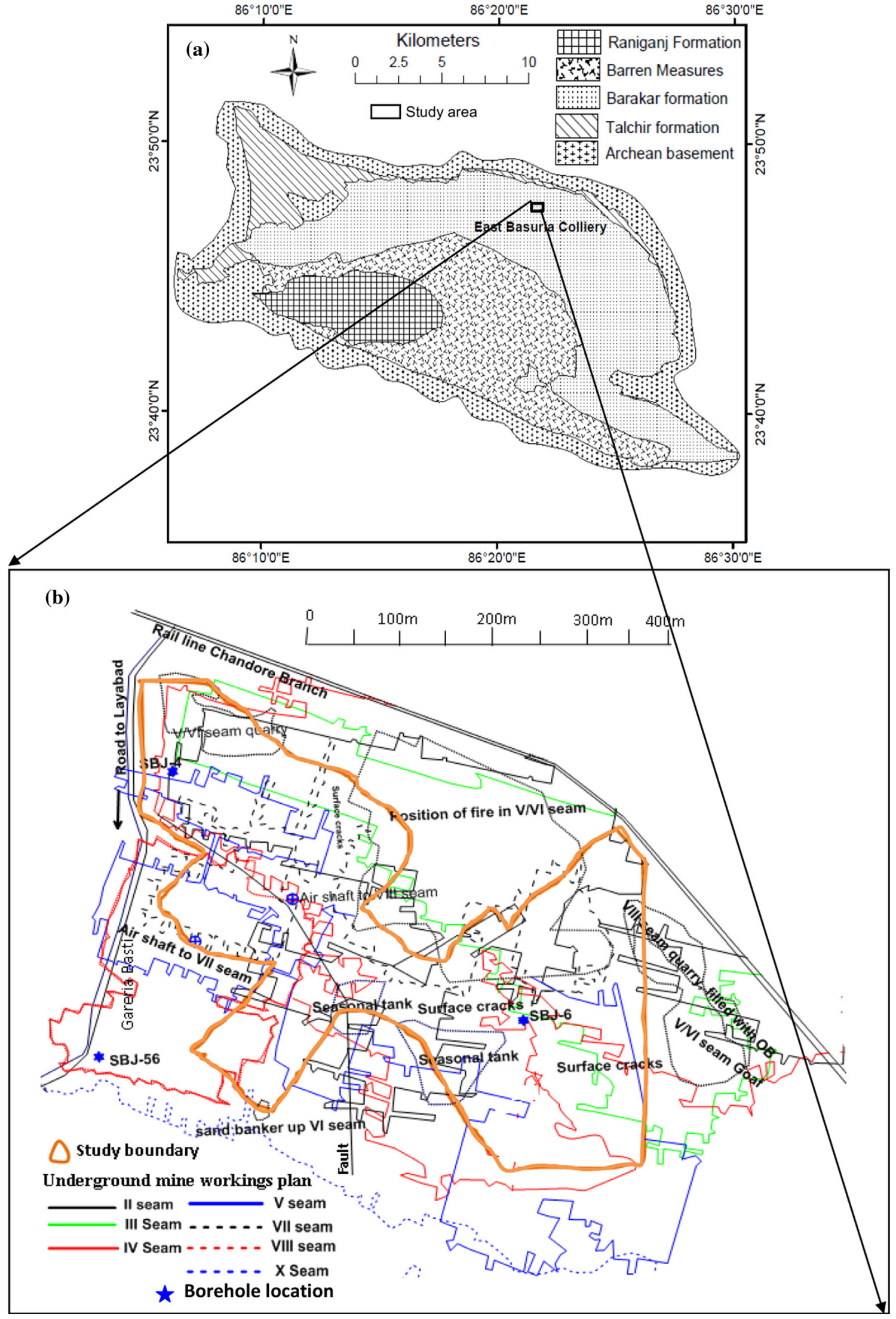

Figure 1. (a) Location map of East Basuria Colliery along with generalized geological map of Jharia coal field and (b) underground mine workings plan (BCCL 2009). 


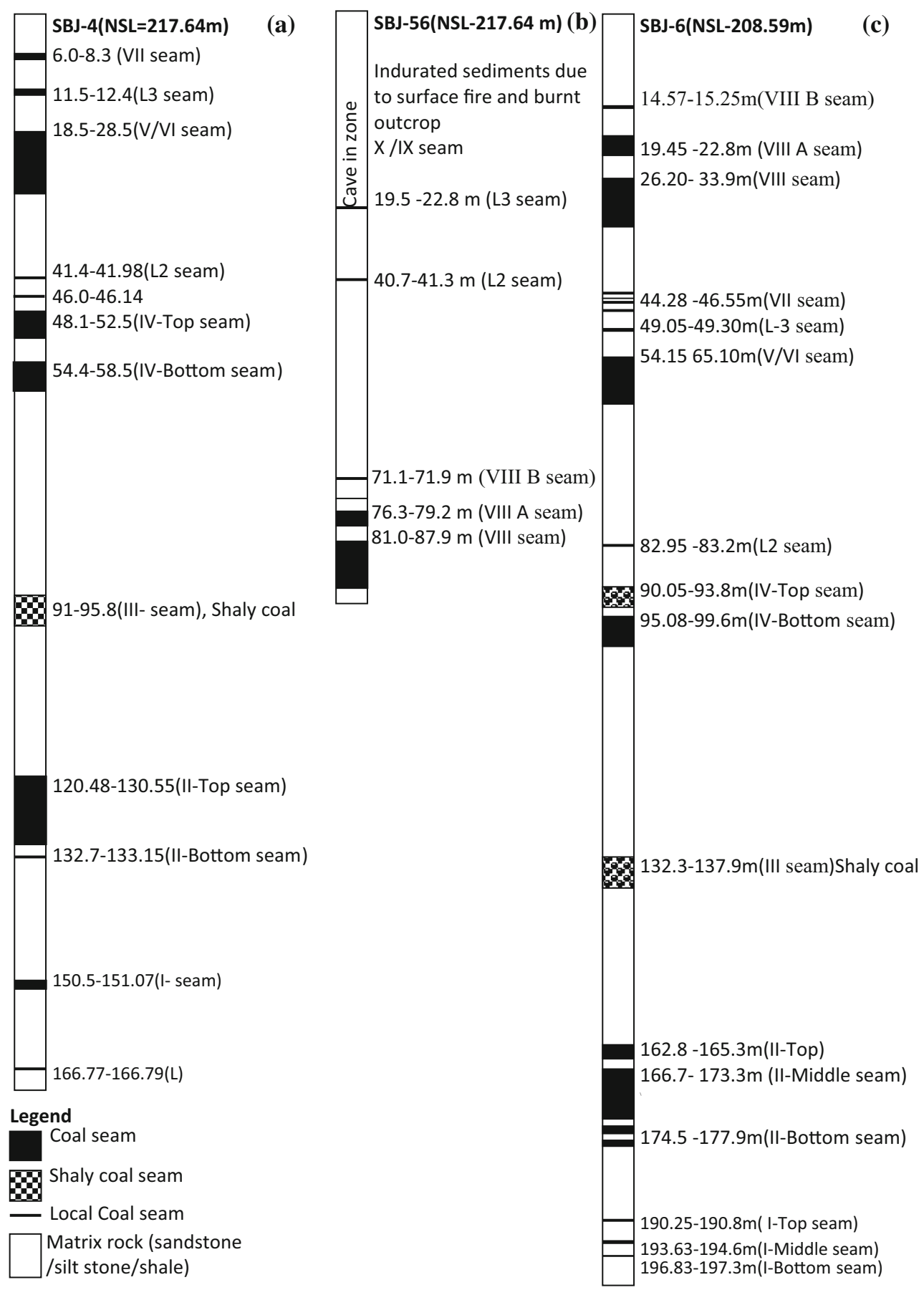

Figure 2. Borehole lithologs (BCCL 2009) showing coal seams and shaly coal seams at different depths. Locations of (a) SBJ-4, (b) SBJ-56, and (c) SBJ-6 are shown in figure 1.

Proton precession magnetometer. The acquired data have been corrected for diurnal variation. Normally, the earth's magnetic field is shifted from the vertical except, the areas near magnetic poles. As a result, the induced magnetization vector is inclined over magnetically susceptible bodies (Mendonca and Silva 1993). This problem is overcome mathematically by transposing the magnetic data to the magnetic pole, termed as reduced to magnetic pole (RTP) (Blakely 1996; Salem et al. 2008; Rajaram 2009; Ide et al. 2011; Shao et al. 2014; Pal et al. 2016a). The RTP of residual magnetic field has been separately processed using tilt derivative (TDR) technique of Miller and Singh (1994) and downward continuation technique of Ma et al. (2013). 
Table 1. Characteristics of coal seams over East Basuria Colliery (BCCL 2009).

\begin{tabular}{|c|c|c|c|c|}
\hline Sl. no. & Seam & $\begin{array}{l}\text { Average } \\
\text { thickness }(\mathrm{m})\end{array}$ & Degree & $\begin{array}{l}\text { Dip } \\
\text { direction }\end{array}$ \\
\hline 1 & $\mathrm{X}$ & 0.82 & 6.71 & $\mathrm{NE} 05^{\circ} \mathrm{SW}$ \\
\hline 2 & IX & 0.91 & 6.71 & $\mathrm{NE} 05^{\circ} \mathrm{SW}$ \\
\hline 3 & VIII & 7.2 & 6.71 & $\mathrm{NE} 05^{\circ} \mathrm{SW}$ \\
\hline 4 & VII & 1.8 & 6.71 & $\mathrm{NE} 05^{\circ} \mathrm{SW}$ \\
\hline 5 & $\mathrm{~V} / \mathrm{VI}$ & 9.45 & 9.46 & $\mathrm{NE} 05^{\circ} \mathrm{SW}$ \\
\hline 6 & IV & 9.57 & 9.46 & $\mathrm{NE} 05^{\circ} \mathrm{SW}$ \\
\hline 7 & III & 3.66 & 9.46 & $\mathrm{NE} 11^{\circ} \mathrm{SW}$ \\
\hline 8 & II & 10.57 & 11.31 & $\mathrm{NE} 15^{\circ} \mathrm{SW}$ \\
\hline 9 & I & 0.85 & 11.31 & $\mathrm{NE} 15^{\circ} \mathrm{SW}$ \\
\hline
\end{tabular}

\subsection{Tilt derivative}

The tilt angle or derivative ratio (TDR) is defined as the arctangent of the ratio of vertical derivative to total horizontal derivative of the magnetic field $f$ (Miller and Singh 1994; Verduzco et al. 2004; Salem et al. 2008; Rajaram 2009):

$$
T D R=\tan ^{-1}\left[\frac{\partial f / \partial z}{\sqrt{(\partial f / \partial x)^{2}+(\partial f / \partial y)^{2}}}\right]
$$

The TDR values vary between $-\pi / 2$ and $+\pi / 2$. The TDR crosses through zero at or near the edge of a vertical source and is negative outside the source region (Miller and Singh 1994). The half-distance between $\pm \pi / 4$ contours gives an approximation of the source depth for vertical contacts. The distance between zero and $+\pi / 4$ or $-\pi / 4$ contour obtained from the TDR represent the depth to the top of the vertical contact (Oruc and Selim 2011; Pal and Majumdar 2015; Narayan et al. 2016; Pal et al. 2016b, c).

\subsection{Downward continuation of magnetic data}

Continuation methods project the observed potential (gravity and magnetic) anomaly field to higher elevations (upward continuation) or lower elevations (downward continuation) and therefore, effectively serve as low-pass and high-pass filters respectively (Khalil 2012), which have been applied in numerous applications (Li and Devriese 2009; Li et al. 2013; Ma et al. 2013). The main advantage of the continuation methods is that the character of the gopotential field anomaly is retained as long as the continuation does not extend into the sources (Khalil 2012). This method is strongly dependent on the sampling interval of the original data and is able to downward-continue only to very shallow depths equal to 2-10 times of the sampling spaces (Xu et al. 2007).

Downward continuation enhances the responses of sources at a depth by effectively bringing the plane of measurement closer to the source. Downward continuation highlights the components of higher wave-number, increases the anomaly resolution of the individual sources and provides a more accurate determination of both horizontal and vertical extents of near-surface magnetic sources (Boschetti 2005). But, its usefulness depends on the elimination of noise, as the computation of downward continuation is unstable and easily distorts the true feature of potential field data (Fedi and Florio 2001, 2002, 2013; Pasteka et al. 2012; Abedi et al. 2013). Upward continuation is a stable computation, at higher heights, which is the contribution of the most extended sources. Because the upward continuation and horizontal derivatives are stable, a combination of upward continuation and horizontal derivative is used to complete the downward continuation of potential field data (Ma et al. 2013). The downward continuation is expressed using the following Taylor series (Even 1936; Fedi and Florio 2002):

$$
\begin{aligned}
T(x, y, h)= & T(x, y, 0)+\frac{\partial T}{\partial z} h+\frac{1}{2 !} \frac{\partial^{2} T}{\partial z^{2}} h^{2} \\
& +\cdots+\frac{1}{m !} \frac{\partial^{m} T}{\partial z^{2}} h^{m}
\end{aligned}
$$

where $T(x, y, h)$ is the potential field at the level of $h, h$ is the continuation height, and $T(x, y, 0)$ is the original potential field data. The computation of upward continuation is expressed using the following Taylor series.

$$
\begin{aligned}
T(x, y,-h)= & T(x, y, 0)-\frac{\partial T}{\partial z} h+\frac{1}{2 !} \frac{\partial^{2} T}{\partial z^{2}} h^{2} \\
& +\cdots+\frac{1}{m !} \frac{\partial^{m} T}{\partial z^{2}}\left(-h^{m}\right)
\end{aligned}
$$

where $T(x, y,-h)$ is the potential field at the level of $-h$. Both continuations require $m$ th order vertical derivatives of the potential field. The high-order vertical derivatives are unstable and can enhance the effect of noises (Florio et al. 2006). So, the Taylor series terms are limited to three neglecting the higher order terms. Equations (1 and 2) are added to give: 


$$
\begin{aligned}
T(x, y, h)= & 2 T(x, y, 0)-T(x, y,-h) \\
& +\frac{\partial^{2} T(x, y, 0)}{\partial z^{2}} h^{2}
\end{aligned}
$$

where the data $T(x, y,-h)$ at the level of $-h$ is computed by the Fourier transform. The effect of the noise is nullified by computing the secondorder vertical derivative through Laplace equation of potential field. The horizontal derivatives for Laplace equation are computed in the space domain. Then, the downward continuation is computed by the combination of the upward continuation
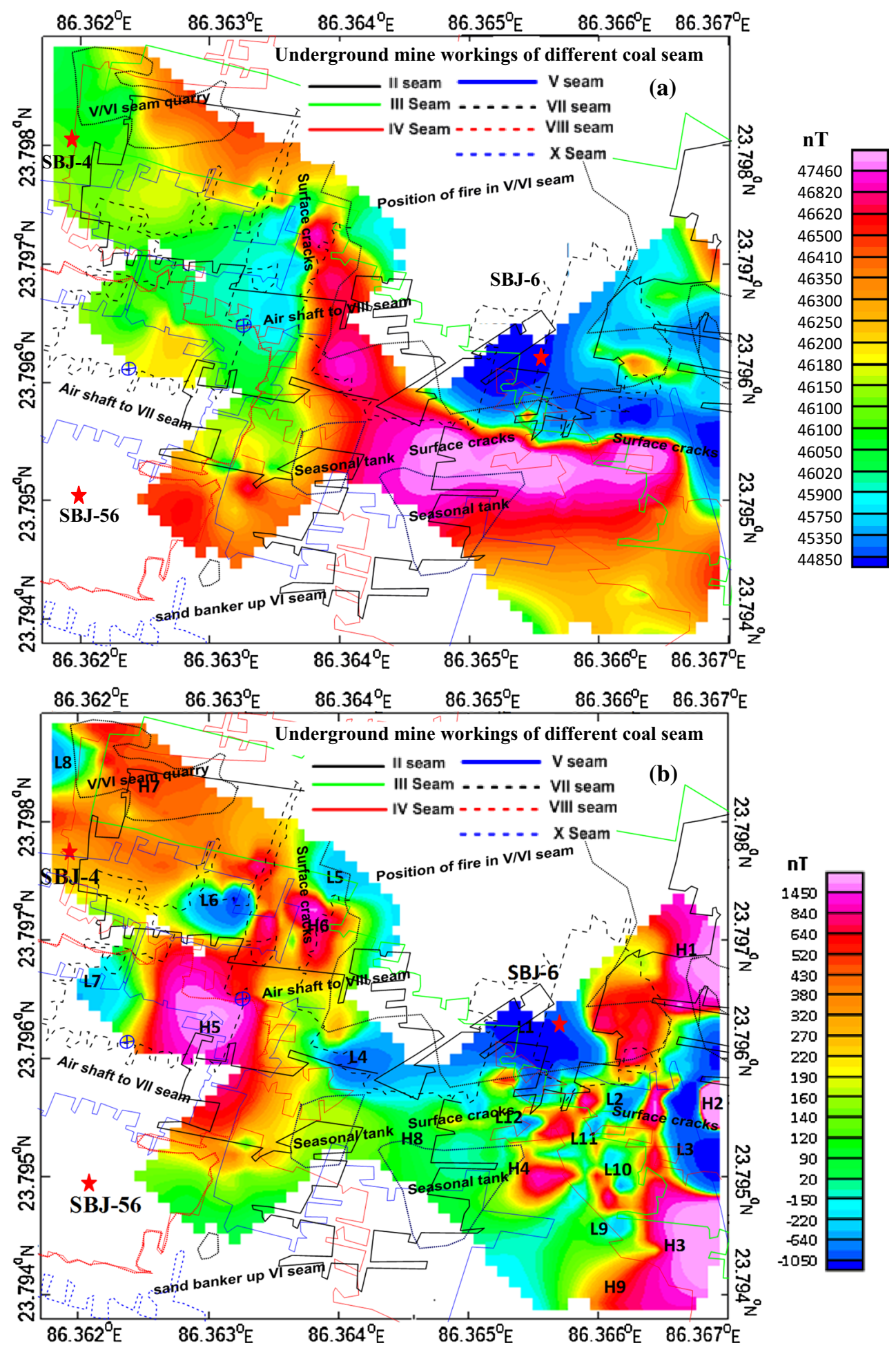

Figure 3. (a) Total magnetic field map and (b) reduction to pole (RTP) map of residual magnetic field with underground mine workings of different coal seams of East Basuria Colliery. 
and horizontal derivatives, which enhances the stability of downward continuation, effectively (Ma et al. 2013). The result is only an approximate value at the level of ' $h$ ' as the higher order terms of the Taylor series are neglected. So, for more accurate result, an iteration method is used to compute the downward continued data (Ma et al. 2013). Initially, equation (3) is used to compute the data at the level of depth $h$.

$$
\begin{aligned}
T_{0}(x, y, h)= & 2 T(x, y, 0)-T(x, y,-h) \\
& +\frac{\partial^{2} T(x, y, 0)}{\partial z^{2}} h^{2} .
\end{aligned}
$$

Further, the data $T_{1}(x, y, 0)$ is generated by upward continuation of the anomaly $T_{0}(x, y, h)$ to the observation level of ' 0 '. Then the difference between the data of $T(x, y, 0)$ and $T_{1}(x, y, 0)$ is

$$
\Delta T_{1}(x, y, 0)=T(x, y, 0)-T_{1}(x, y, 0) .
$$

The equation (3) is used to downward-continue the data $\Delta T_{1}(x, y, 0)$ to the level of $h$, and the result is given by

$$
\begin{aligned}
\Delta T_{1}(x, y, h)= & 2 \Delta T_{1}(x, y, 0)-\Delta T_{1}(x, y,-h) \\
& +\frac{\partial^{2} \Delta T_{1}(x, y, 0)}{\partial z^{2}} h^{2}
\end{aligned}
$$

where $\Delta T_{1}(x, y, h)$ is the downward continuation of the data $\Delta T_{1}(x, y, 0)$ to the depth level of $h$, and $\Delta T_{1}(x, y,-h)$ is the upward continuation of the data $\Delta T_{1}(x, y, 0)$ to the elevation level of $-h$. Now, the potential field data at the level of depth $h$ is rewritten as (Ma et al. 2013):

$$
T_{1}(x, y, h)=T_{0}(x, y, h)-\Delta T_{1}(x, y, h) .
$$

This iteration process is repeated until the root mean square (RMS) error of the data $\Delta T_{m}(x, y, 0)$ is less than a given value, and the final downward continuation data at the level of $h$ can be expressed as (Ma et al. 2013):

$$
\begin{aligned}
T_{m}(x, y, h)= & T_{0}(x, y, h)+\Delta T_{1}(x, y, h) \\
& +\cdots+\Delta T_{m}(x, y, h) .
\end{aligned}
$$

Ma et al. (2013) have established that the iterative downward continuation through combination of upward continuation using Taylor series expansion

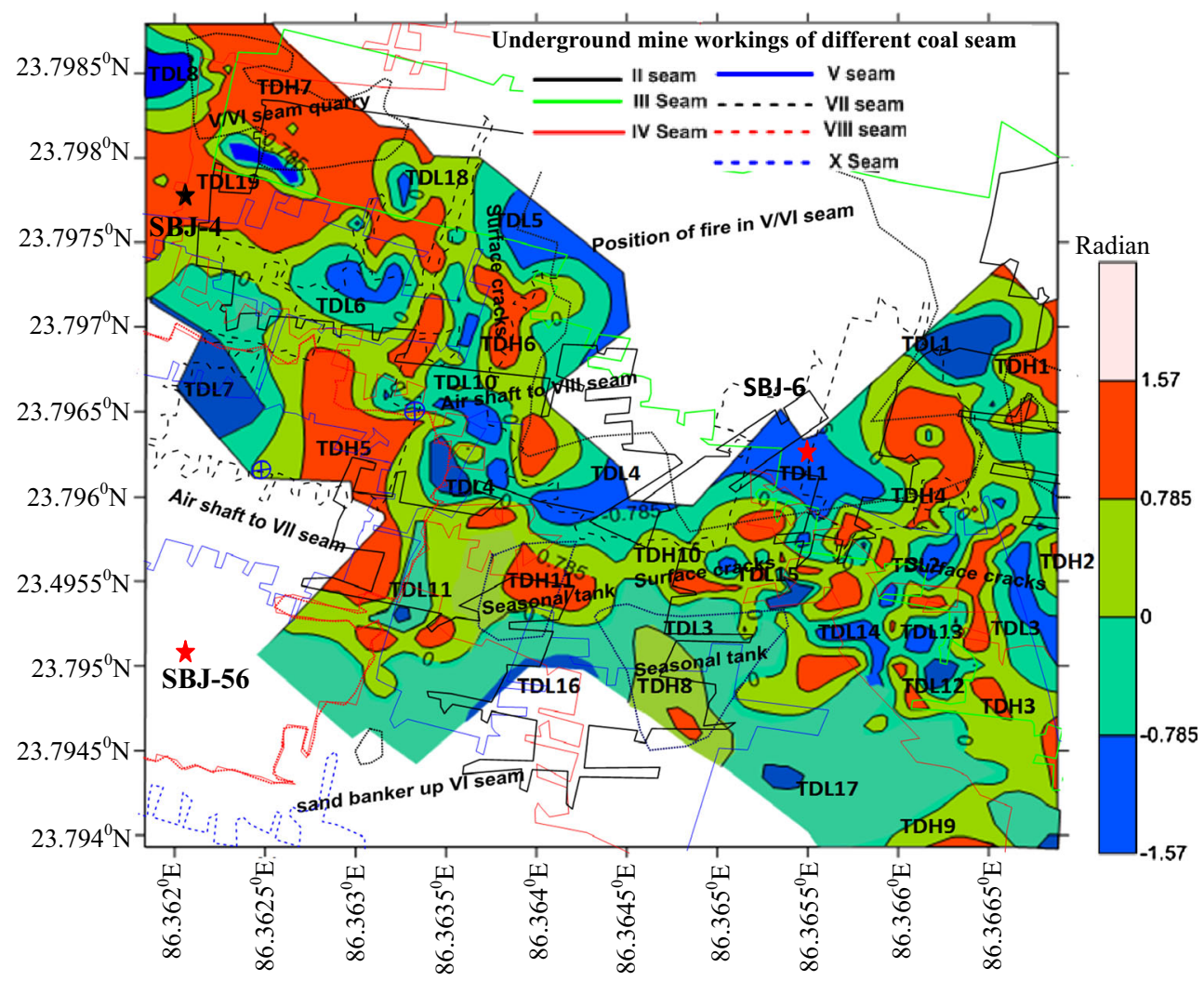

Figure 4. Tilt derivative map generated from RTP of residual magnetic field data of East Basuria Colliery. Underground mine workings of different coal seams are overlayed on the tilt derivative map. Causative magnetic source zone characterized by positive tilt derivative (TDH1-TDH11) and negative tilt derivative (TDL1-TDL19) are shown. 


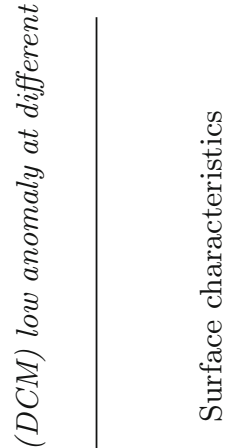

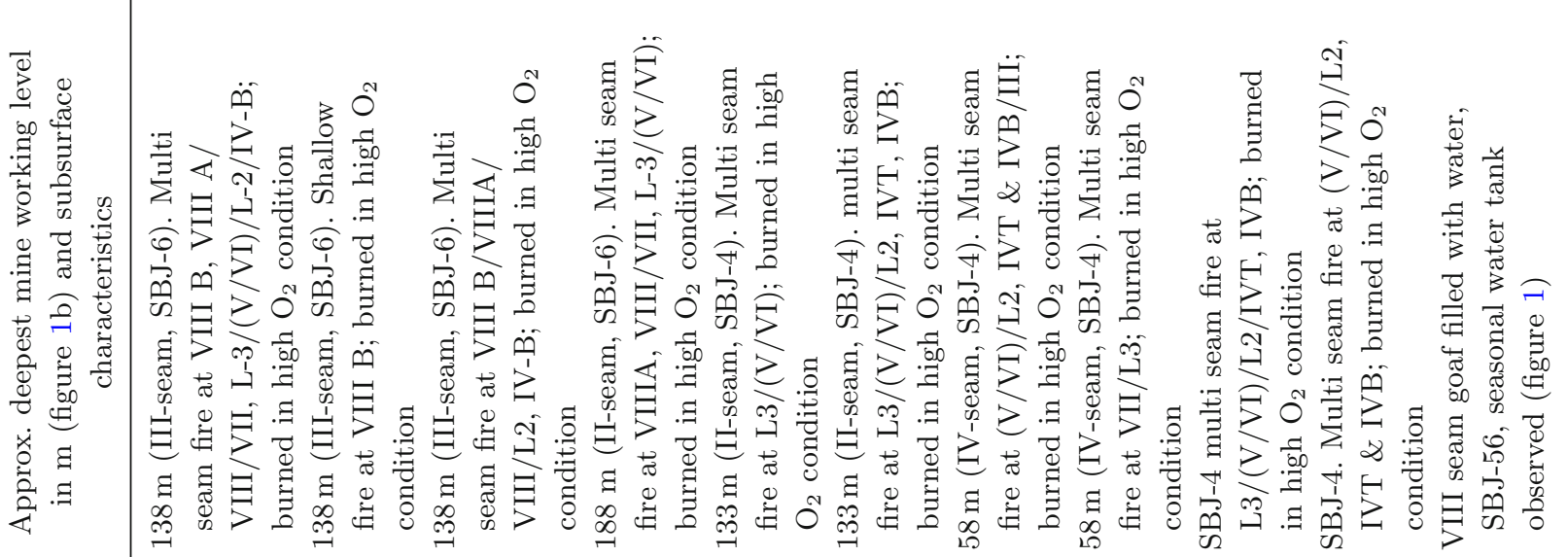

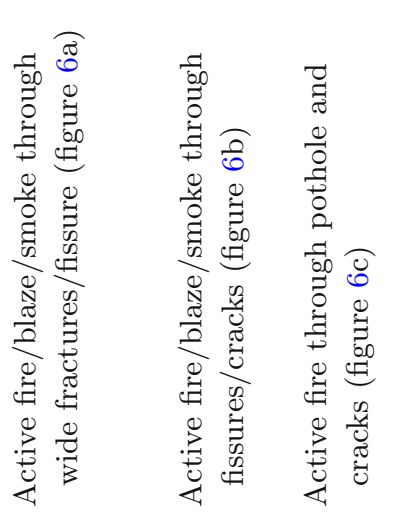

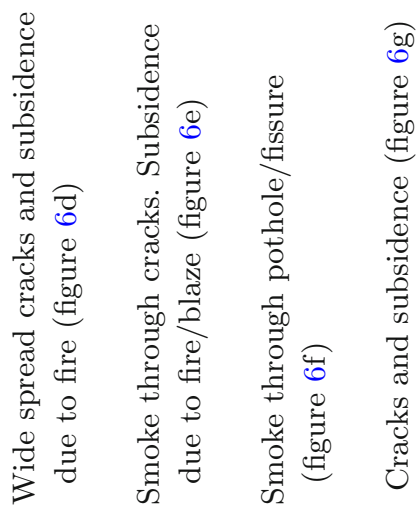

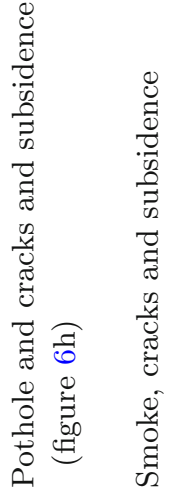

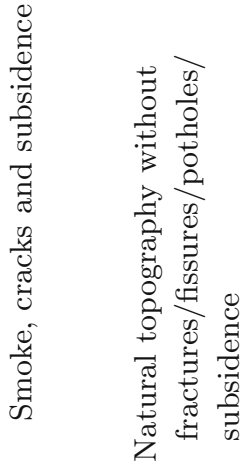

气ัँ

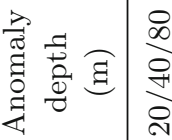

$\stackrel{\stackrel{\infty}{\circ}}{\stackrel{N}{\circ}}$

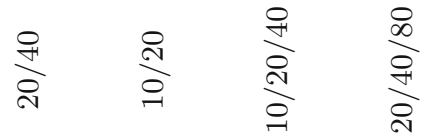

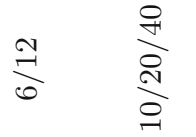

$\stackrel{ }{\stackrel{9}{2}}$

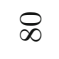

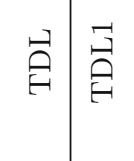

尊爵

蓄量

高音

高

$\frac{9}{8}$

$\stackrel{\leftrightarrow}{\stackrel{十}{\leftrightarrows}}$

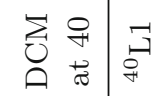

일

$\stackrel{9}{3}$

蓓

妾竞

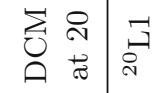

్ำ

党

ำ

洜

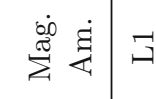

곡

$\dot{\pi} \dot{\dot{g}}-$

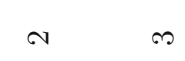

H

10

0

ト

$\infty$

o 

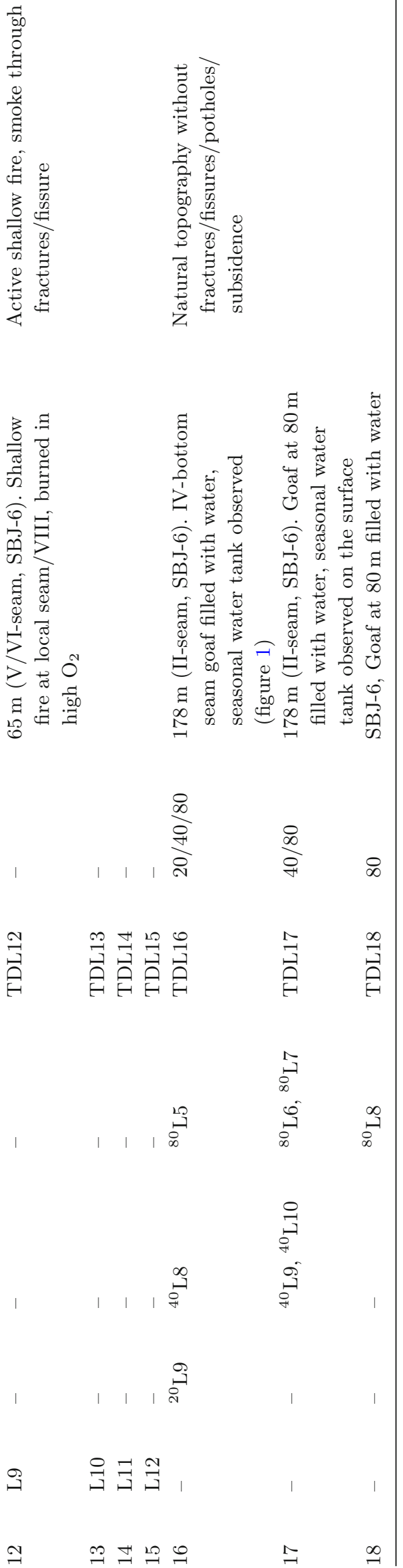

and horizontal derivatives using Laplace equation provide more stable results and is less sensitive to noise compared to the traditional method.

\section{Results and discussions}

The diurnal corrections have been applied on the recorded magnetic readings based on the drift in the base station readings. The spikes and dropped signals have been removed and only the consistent readings have been used for processing. Total intensity magnetic anomaly map with underground mine workings of different coal seam over the area is shown in figure 3(a). Total intensity magnetic anomaly varies from $\sim 44,850$ to $\sim 47,640 \mathrm{nT}$. The residual map has been prepared by subtracting the Earth's main field from the magnetic data of the area. The residual magnetic data have been reduced to north magnetic pole (RTP) to remove the lateral shifts and asymmetries caused by the local orientation of the magnetic anomaly. Reduction to pole (RTP) map of residual magnetic field with underground mine workings of different coal seam of East Basuria Colliery is shown in figure 3(b). RTP magnetic anomaly varies from $\sim-1050$ to $1450 \mathrm{nT}$. Low (L1-L12) and high (H1-H9) RTP magnetic anomalies have been delineated from figure $3(\mathrm{~b})$, as different surface anomaly distribution.

Tilt derivative map has been generated from RTP data of residual magnetic data of East Basuria Colliery (figure 4). The TDR image shows contours of 0 and $\pm \pi / 4$ ( 0 to \pm 0.785$)$ radian. This figure indicates that the TDR anomaly map could be utilized for recognition of the horizontal location and extent of edges of various sources assuming vertical contact model. The zero contours estimate the horizontal location of abrupt lateral changes in the subsurface features. The TDR map highlights short wavelengths. The half distance between $\pm \pi / 4$ contours has been used to estimate the depth of the edge of the magnetized sources. Totally 11 causative source zones characterized by positive tilt derivative responses have been identified (TDH1TDH11). Further, 19 causative source zones characterized by negative tilt derivative response have been identified (TDL1-TDL19). Details of positive and negative tilt derivative anomaly and corresponding inferred average depths to the top of principal anomaly, their relation with equivalent approximate deepest mine working level, coal seam occurrences and their surface characteristics are given in tables 2 and 3. 


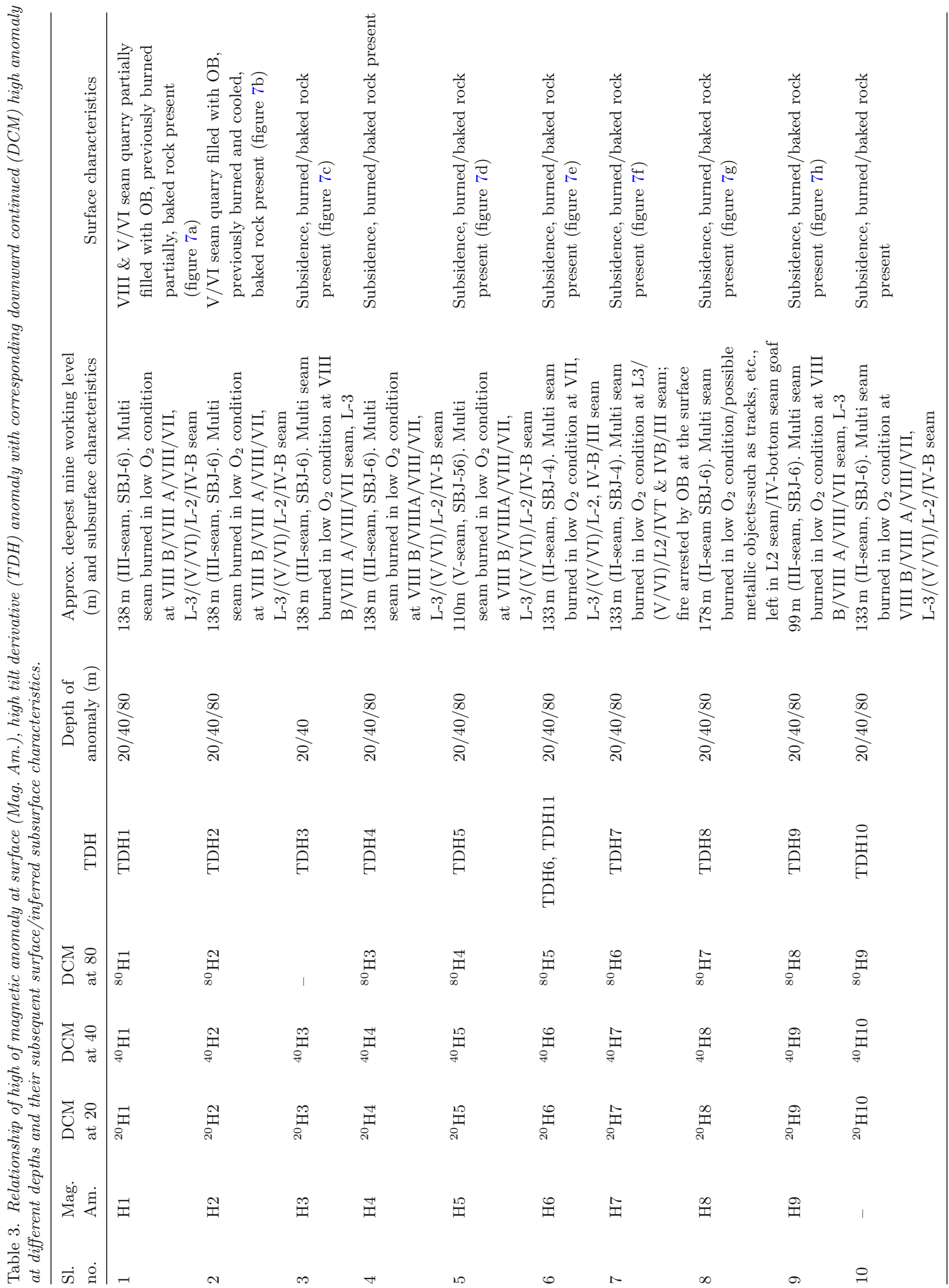




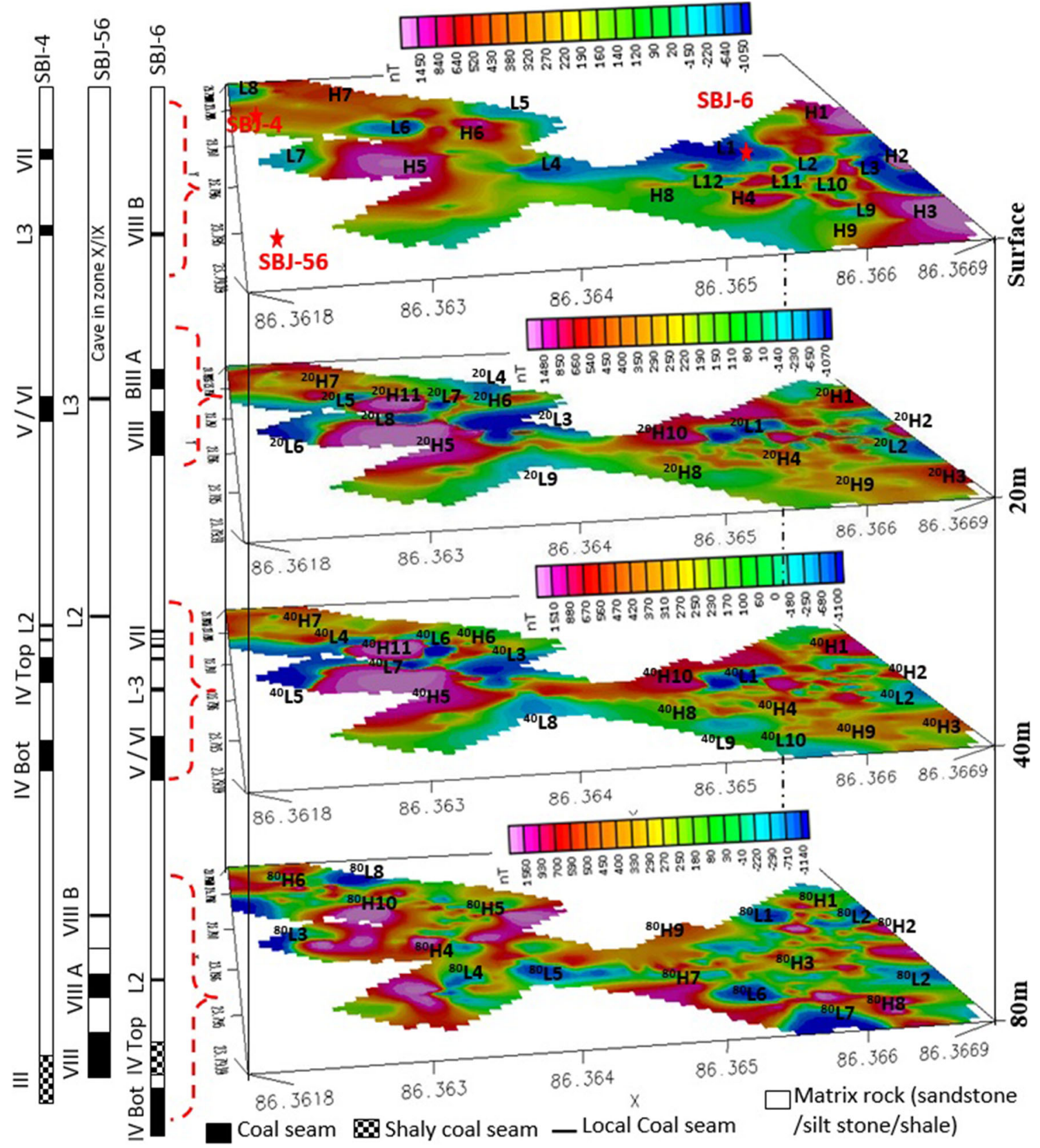

Figure 5. 3D model of magnetic anomaly distribution indicating low anomaly (L1-L12 at surface, ${ }^{20} \mathrm{~L} 1-{ }^{20} \mathrm{~L} 9$ at $20 \mathrm{~m}$ depth, ${ }^{40} \mathrm{~L} 1-{ }^{40} \mathrm{~L} 10$ at $40 \mathrm{~m}$ depth and ${ }^{80} \mathrm{~L} 1-{ }^{80} \mathrm{~L} 8$ at $80 \mathrm{~m}$ depth) and high anomaly (H1-H9 at surface, ${ }^{20} \mathrm{H} 1-{ }^{20} \mathrm{H} 10$ at depth of $20 \mathrm{~m},{ }^{40} \mathrm{H} 1-{ }^{40} \mathrm{H} 10$ at $40 \mathrm{~m}$ depth and ${ }^{80} \mathrm{H} 1-{ }^{80} \mathrm{H} 9$ at $80 \mathrm{depth}$ ) regions are generally caused by coal active fire and coal fire-free regions, respectively. Possible coal seams corresponding to the burning zones are shown with dashed line of range.

A schematic 3D model showing magnetic anomaly distribution at the surface and downward continued anomaly at different depths, viz., 20, 40, and $80 \mathrm{~m}$ has been generated (figure 5). From the 3D model (figure 5), the low magnetic anomaly regions, i.e.,

(i) L1-L12 (12 in numbers) at surface (figure $3 \mathrm{~b})$,

(ii) ${ }^{20} \mathrm{~L} 1-{ }^{20} \mathrm{~L} 9$ (nine in numbers) at $20 \mathrm{~m}$ depth,

(iii) ${ }^{40} \mathrm{~L} 1-{ }^{40} \mathrm{~L} 10$ (10 in numbers) at $40 \mathrm{~m}$ depth, and (iv) ${ }^{80} \mathrm{~L} 1-{ }^{80} \mathrm{~L} 8$ (eight in numbers) at $80 \mathrm{~m}$ depth have been prominently identified.

Further, high magnetic anomaly regions i.e.,

(i) H1-H9 (nine in numbers) at surface (figure 3b),

(ii) ${ }^{20} \mathrm{H} 1-{ }^{20} \mathrm{H} 10$ (10 in numbers) at depth of $20 \mathrm{~m}$,

(iii) ${ }^{40} \mathrm{H} 1-{ }^{40} \mathrm{H} 10$ (10 in numbers) at $40 \mathrm{~m}$ depth, and

(iv) ${ }^{80} \mathrm{H} 1-{ }^{80} \mathrm{H} 9$ (nine in numbers) at 80 depth have been clearly delineated from the $3 \mathrm{D}$ model (figure 5). 

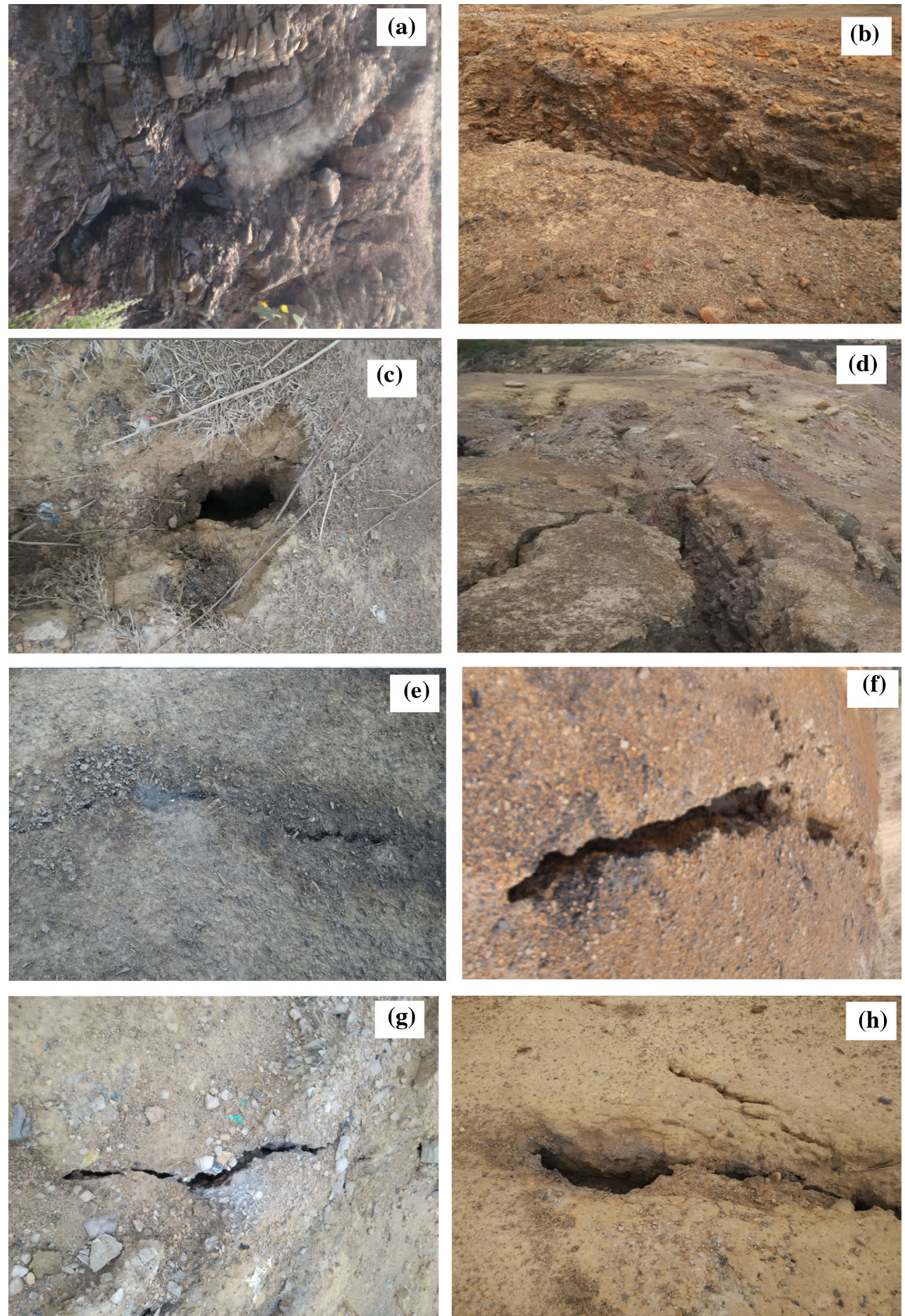

Figure 6. ( $\mathbf{a}-\mathbf{h})$ are field photographs of active fire regions showing smokes, fissures, cracks, potholes, etc., near L1-L8, respectively.

The red regions show the enhancement of magnetic anomalies with respect to ambient magnetic anomalies over the area. The blue regions are the location where the magnetic anomalies are reduced with respect to natural conditions. Field photographs over active fire through fissures, cracks, potholes, etc., near L1, L2, L3, L4, L5, L6, L7 and L8, are shown in figure $6(\mathrm{a}-\mathrm{h})$; respectively. Further, field photographs of burnt/baked rocks near H1, H2, H3, H5, H6, H7, H8, H9, are shown in figure $7(\mathrm{a}-\mathrm{h})$; respectively. It is inferred that the red regions indicate the locations that were heated and subsequently cooled. The blue regions are the location where some portion of the formation is 

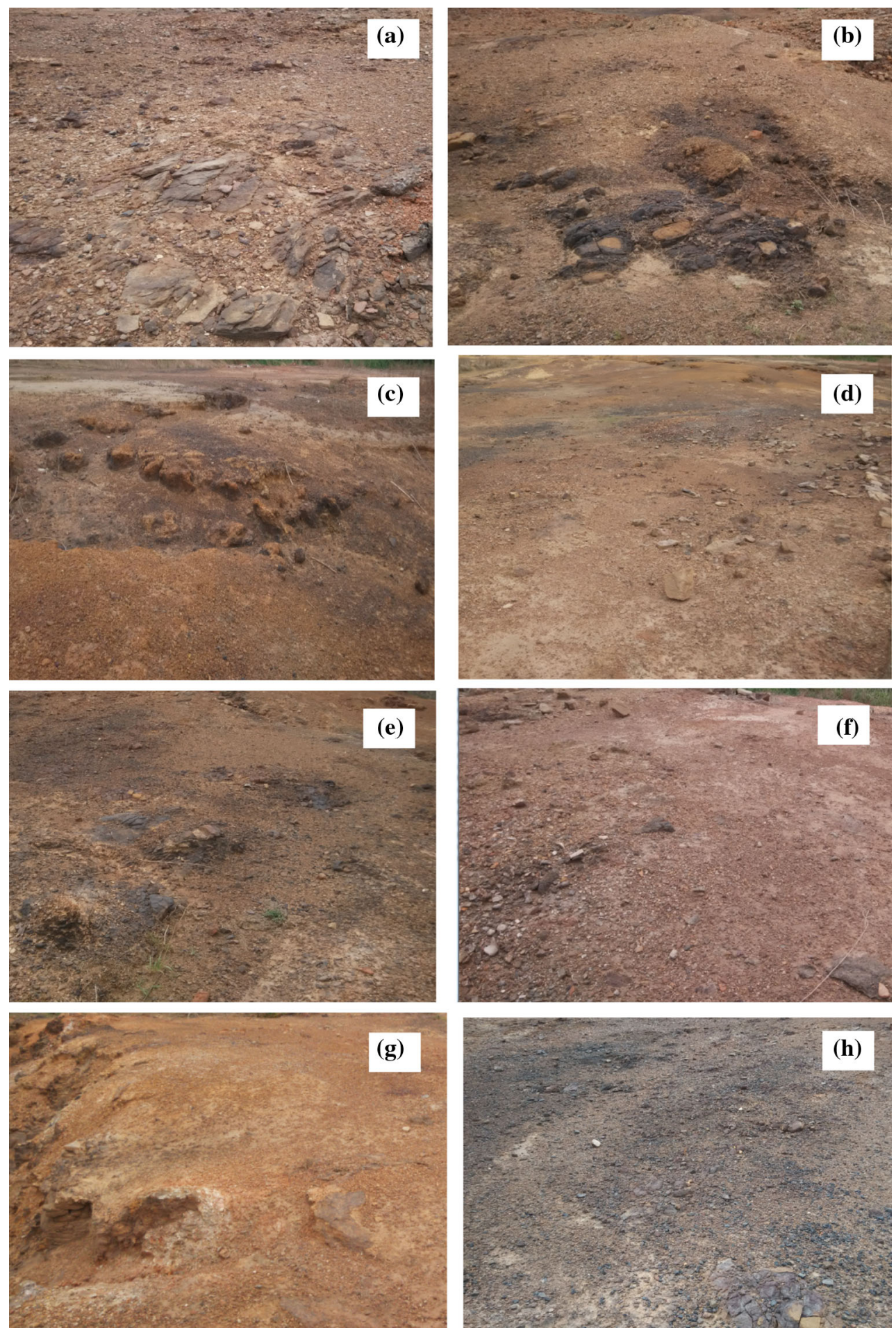

Figure 7. (a-h) are field photographs of burnt/baked rocks near H1-H9, respectively.

under fire and heated above the Curie temperature. The light-green regions are inferred to be unaffected by the coal fire. Details of high and low magnetic anomalies and their subsequent inferred depths of subsurface features (figure 5), their relationship to the corresponding approximate deepest mine working level (figure 1b), coal seam occurrences (figure 2) and their surface characteristics (figures 6 and 7 ) are described in tables 2 and 3. Further, relationship of magnetic (low, L1L12 and high, H1-H9) anomaly at surface with corresponding downward continued anomaly map 
at different levels and their subsequent surface and subsurface characteristics are also explained in tables 2 and 3 on the basis of comprehensive observations from figures 1, 2, 5, 6 and 7 . The occurrences of coal seam fires and complex nature of fire propagation may not be always perfectly corroborated with the borehole lithologs (figure 2) due to varying slope and dip of coal seam.

Fourteen low anomaly locations, viz.,

(1) $\mathrm{L} 1 /{ }^{20} \mathrm{~L} 1 /{ }^{40} \mathrm{~L} 1 /{ }^{80} \mathrm{~L} 1 / \mathrm{TDL} 1$ (figure $5 \mathrm{a}$ );

(2) L2/TDL2 (figure 6b);

(3) L3 $/{ }^{20} \mathrm{~L} 2 /{ }^{40} \mathrm{~L} 2 /{ }^{80} \mathrm{~L} 2 / \mathrm{TDL} 3$ (figure $6 \mathrm{c}$ );

(4) $\mathrm{L} 4 /{ }^{20} \mathrm{~L} 3 /{ }^{40} \mathrm{~L} 3 / \mathrm{TDL} 4$ (figure $6 \mathrm{~d}$ );

(5) $\mathrm{L} 5 /{ }^{20} \mathrm{~L} 4 / \mathrm{TDL} 5$ (figure $6 \mathrm{e}$ );

(6) $\mathrm{L} 6 /{ }^{20} \mathrm{~L} 5 /{ }^{40} \mathrm{~L} 4 / \mathrm{TDL} 6$ (figure $6 \mathrm{f}$ );

(7) $\mathrm{L} 7 /{ }^{20} \mathrm{~L} 6 /{ }^{40} \mathrm{~L} 5 /{ }^{80} \mathrm{~L} 3 / \mathrm{TDL} 7$ (figure $6 \mathrm{~g}$ );

(8) L8/TDL8/TDL19 (figure 6h);

(9) ${ }^{20} \mathrm{~L} 7 /{ }^{40} \mathrm{~L} 6 /$ TDL9;

(10) ${ }^{20} \mathrm{~L} 8 /{ }^{40} \mathrm{~L} 7 / \mathrm{TDL} 10 ;$

(11) L9/TDL12;

(12) L10/TDL13;

(13) L11/TDL14; and

(14) $\mathrm{L} 12 /$ TDL15

have been inferred for coal fire affected area with high $\mathrm{O}_{2}$ circulation through wide spread crack/pot holes/fissures, etc.

Four low anomaly locations, viz.,

(1) ${ }^{80}$ L4 by VIII-seam goaf;

(2) ${ }^{20} \mathrm{~L} 9 /{ }^{40} \mathrm{~L} 8 /{ }^{80} \mathrm{~L} 5 / \mathrm{TDL} 16$ by IV-Bottom seam goaf;

(3) ${ }^{40} \mathrm{~L} 9 /{ }^{40} \mathrm{~L} 10 /{ }^{80} \mathrm{~L} 6 /{ }^{80} \mathrm{~L} 7 / \mathrm{TDL} 17$ by goaf at $80 \mathrm{~m}$;

(4) ${ }^{80} \mathrm{~L} 8 /$ TDL18 by IV-Bottom seam goaf,

have been inferred for the goaf filled with water.

Ten high anomaly locations such as

(1) $\mathrm{H} 1 /{ }^{20} \mathrm{H} 1 /{ }^{40} \mathrm{H} 1 /{ }^{80} \mathrm{H} 1 / \mathrm{TDH} 1$ (figure $7 \mathrm{a}$ );

(2) $\mathrm{H} 2 /{ }^{20} \mathrm{H} 2 /{ }^{40} \mathrm{H} 2 /{ }^{80} \mathrm{H} 2 / \mathrm{TDH} 2$ (figure $7 \mathrm{~b}$ );

(3) $\mathrm{H} 3 /{ }^{20} \mathrm{H} 3 /{ }^{40} \mathrm{H} 3 / \mathrm{TDH} 3$ (figure $7 \mathrm{c}$ );

(4) $\mathrm{H} 4 /{ }^{20} \mathrm{H} 4 /{ }^{40} \mathrm{H} 4 /{ }^{80} \mathrm{H} 3 / \mathrm{TDH} 4$;

(5) $\mathrm{H} 5 /{ }^{20} \mathrm{H} 5 /{ }^{40} \mathrm{H} 5 /{ }^{80} \mathrm{H} 4 / \mathrm{TDH} 5$ (figure $7 \mathrm{~d}$ );

(6) $\mathrm{H} 6 /{ }^{20} \mathrm{H} 6 /{ }^{40} \mathrm{H} 6 /{ }^{80} \mathrm{H} 5 / \mathrm{TDH} 6 / \mathrm{TDH} 11$ (figure $7 \mathrm{e}$ );

(7) $\mathrm{H} 7 /{ }^{20} \mathrm{H} 7 /{ }^{40} \mathrm{H} 7{ }^{80} \mathrm{H} 6 / \mathrm{TDH} 7$ (figure $7 \mathrm{f}$ );

(8) ${ }^{20} \mathrm{H} 10 /{ }^{40} \mathrm{H} 10 /{ }^{80} \mathrm{H} 9 / \mathrm{TDH} 8$ (figure $7 \mathrm{~g}$ );

(9) $\mathrm{H} 9 /{ }^{20} \mathrm{H} 9 /{ }^{40} \mathrm{H} 9 /{ }^{80} \mathrm{H} 8 / \mathrm{TDH} 9$ (figure $7 \mathrm{~h}$ ); and

(10) ${ }^{20} \mathrm{H} 10 /{ }^{40} \mathrm{H} 10 /{ }^{80} \mathrm{H} 9 / \mathrm{TDH} 10$

have been inferred to be burned in low $\mathrm{O}_{2}$ circulation and cooled.

The magnetic field intensity over an area is the aggregate of all the magnetic anomalies associated with various ferromagnetic, antiferromagnetic, paramagnetic and diamagnetic formations. Generally, the occurrence of ferromagnetic minerals and the degree of alignment of the magnetic moments in the overlying formations (Hooper 1987) result in positive magnetic susceptibility. The magnetization of overlying formations comprising traces of magnetic minerals looses due to heating by coal fire to the Curie temperature. After cooling, the magnetic moments of the thermally altered overlying formation align themselves in the Earth's ambient magnetic field with relatively high magnetization (Gielisch 2007; Ide et al. 2011). The thermal alteration process is mainly controlled by presence of $\mathrm{O}_{2}$ at high temperature environment $\left(200^{\circ}-1000^{\circ} \mathrm{C}\right)$, generally witnessed within coal fires affected regions. The magnetite $\left(\mathrm{Fe}_{3} \mathrm{O}_{4}\right)$ is a ferromagnetic formation (Hooper 1987) which may be generated under the low $\mathrm{O}_{2}$ environment in deeper multi seam fire or shallow coal seam fire blanketed by clay soil (Ide et al. 2011). The rocks with low permeability and low porosity such as siltstone, shale, etc., arrest the $\mathrm{O}_{2}$ circulation to the underneath coal fires, which offer an ideal environment for generation of magnetite. The hematite $\left(\mathrm{Fe}_{2} \mathrm{O}_{3}\right)$ is an antiferromagnetic formation and it does not enhance the magnetization of a region which may be generated in shallow seam fire with high $\mathrm{O}_{2}$ circulation through wide spread fissures, cracks, pot holes, etc. (Ide et al. 2011).

A huge amount of diamagnetic gases, viz., Methane $\left(\mathrm{CH}_{4}\right)$, Carbon dioxide $\left(\mathrm{CO}_{2}\right)$, Ammonia $\left(\mathrm{NH}_{3}\right)$, Sulphur dioxide $\left(\mathrm{SO}_{2}\right)$; Carbon monoxide (CO), Nitrogen $\left(\mathrm{N}_{2}\right)$, Hydrogen, Selenium (Se), Arsenic (As), Mercury (Hg), water vapour, tar vapours, organic sulphur, hydrogen chlorides and inorganic chlorides, various polycyclic aromatic/ unsaturated hydrocarbons, etc., are generated in underground active coal fire under a complex chaotic process comprising different indistinct parameters (Engle et al. 2013; Gürdal et al. 2015; Pal et al. 2016a). Additionally, pyrolysis and heating of coal to graphitizing temperature results in production of a small amount of the paramagnetic formation and a large amount of the diamagnetic formation (Jenkins and Kawamura 1976). These are the possible cumulative sources for low magnetic anomaly. Further, goafs at different seams filled with air/water which are diamagnetic in nature and generate magnetic field against the external ambient magnetic field. Thus, it indicates low magnetic anomaly. 


\section{Conclusions}

Fourteen low anomaly locations have been identified as coal fire affected area due to high $\mathrm{O}_{2}$ circulation through wide spread cracks/potholes/fissures, etc. (table 2). Four low anomaly locations have been inferred corresponding to the goafs filled with water (table 2). Ten high anomaly locations have been delineated as burned in low $\mathrm{O}_{2}$ environment and subsequently, cooled (table 3 ). The coal fire affected areas have been delineated using magnetic anomaly map (at the surface, figures $3 \mathrm{~b}$ and 5 ) after pole reduction, which correlate well with the surface manifestations (figures 1, 6; tables 2, $3)$. Most of the magnetic anomalies are matched with coal fire locations observed at the surface (figures 6 and 7 ) and further, correlated with corresponding tilt derivative anomalies (figure 4) and downward continued anomalies at different depths (figure 5). Their subsequent surface (figures 6 and 7 ) and subsurface characteristics (figures 4 and 5) are explained with better agreement (tables 2 and 3). Approximate source depths of principle anomaly inferred from 3D model of downward continued anomaly distribution (figure 5) are correlated well with multi seam occurrences (figure 2), mine working levels (figure $1 \mathrm{~b}$ ), tilt derivative anomalies (figure 4) and surface manifestation (figures 6 and 7 ). These results prove the efficacy of integrated study comprising downward continuation and tilt derivative methods of magnetic data for characterization of concealed coal fire in East Basuria Colliery, Jharia coal field, India. This could be done very effectively by repeated study of the affected area in time lapsed magnetic survey.

\section{Acknowledgements}

The authors are thankful to Department of Science and Technology, Govt. of India, for funding the project (SB/S4/ES-640/2012) on geotechnical characterization of Jharia coal field area using Geophysical techniques. Authors are grateful to Dr N Purnachandra Rao, Associate Editor, JESS and anonymous referees as well as the editors of the Journal for their valuable suggestions. The authors wish to thank the Director, IIT(ISM), Dhanbad and HOD, Department of Applied Geophysics, ISM, Dhanbad for their support in this study.

\section{References}

Abedi M, Gholami A and Norouzi G H 2013 A stable downward continuation of airborne magnetic data: A case study for mineral prospectivity mapping in Central Iran; Comput. Geosci. 52 269-280.

Agarwal R, Singh D, Chauhan D S and Singh K P 2006 Detection of coalmine fires in the Jharia coal field using NOAA/AVHRR data; J. Geophys. Eng. 3 212-218.

BCCL 2009 East Basuria Colliery plan of underground working and Borehole lithologs.

Bharti A K, Pal S K and Vaish J 2014 Application of self-potential method for coal fire detection over Jharia Coal field. 51st Annual convention of Indian Geophysical Union, Kurukshetra University, Kurukshetra, 19-21 November, pp. 59-62.

Bharti A K, Pal S K, Priam P, Kumar S, Shalivahan and Yadav P K 2016a Subsurface cavity detection over Patherdih colliery, Jharia Coalfield, India using electrical resistivity tomography; Environ. Earth Sci. 75(5) 1-17.

Bharti A K, Pal S K, Priyam P, Pathak V K, Kumar R and Ranjan S K 2016b Detection of illegal mine voids using electrical resistivity tomography: The case-study of Raniganj coalfield (India); Eng. Geol. 213 120-132.

Bharat Coking Coal 2003 Brief history of BCCL; Dhanbad, Bharat Coking Coal Ltd., http://bccl.nic.in/About-us. htm.

Bhattacharya B B and Shalivahan 2016 Geoelectric Methods: Theory and Application; McGraw Hill Education (India) Pvt. Ltd., 735p.

Blakely R 1996 Potential Theory in Gravity and Magnetic Applications; Cambridge University Press, Cambridge, UK, 435p.

Boschetti F 2005 Improved edge detection and noise removal in gravity maps via the use of gravity gradients; J. Appl. Geophys. 57 213-225.

Chatterjee R S 2006 Coal fire mapping from satellite thermal IR data: A case example in Jharia coalfield, Jharkand, India; ISPRS J. Photogram. Rem. Sens. 60 113-128.

Chatterjee R S, Wahiduzzman Md, Shah A, Raju E V R, Lakhera R C and Dadhawal V K 2007 Dynamics of coal fire in Jharia Coal Field, Jharkhand, India during the 1990s as observed from space; Curr. Sci. 92(1) 61-68.

CMPDI 2003 Scheme for dealing with fire for protection of KT Link Line at East Basuria colliery; 16p.

Coal International 2003 Coal India plans 53 mine closures; Industry News 251(3) 107.

Das P, Pal S K, Mohanty P R, Priyam P, Bharti A K and Kumar R 2017 Abandoned mine galleries detection using electrical resistivity tomography method over Jharia coal field, India; J. Geol. Soc. India (in press).

Engle M A, Olea R A, O'Keefe J M K, Hower J C and Geboy N J 2013 Direct estimation of diffuse gaseous emissions from coal fires: Current methods and future directions; Int. J. Coal Geol. 112 164-172.

Even H M 1936 The place of the vertical gradient in gravitational interpretation; Geophysics 1 127-136.

Fedi M and Florio G 2001 Detection of potential fields source boundaries by enhanced horizontal derivative method; Geophys. Prospect. 49 40-58. 
Fedi M and Florio G 2002 A stable downward continuation by using ISVD method; Geophys. J. Int. 151 146-156.

Fedi M and Florio G 2013 Determination of the maximumdepth to potential field sources by a maximum structural index method; J. Appl. Geophys. 88 154-160.

Florio G, Fedi M and Pasteka R 2006 On the application of Euler deconvolution to the analytic signal; Geophys. $\mathbf{7 1}$ L87-L93.

Gangopadhyay P K 2006 Application of remote sensing to identify coalfires in the Raniganj coalbelt, India; Int. J. Appl. Earth. Observ. Geoinfor. 8 188-195.

Ghose M K and Majee S R 2000 Sources of air pollution due to coal mining and their impacts in Jharia coal field; Env. Int. 26 81-85.

Gielisch H 2007 Detecting concealed coal fires; Rev. Eng. Geol. 18 199-210.

Gürdal G, Hoşgörmez H, Özcan D, Li X, Liu H and Song W 2015 The properties of Çan Basin coals (Çanakkale Turkey): Spontaneous combustion and combustion byproducts; Int. J. Coal Geol. 138 1-15.

Hooper R L 1987 Factors affecting the magnetic susceptibility of baked rocks above a burned coal seam; Int. J. Coal Geol. 9 157-169.

Ide T S and Orr Jr F M 2011 Comparison of methods to estimate the rate of $\mathrm{CO}_{2}$ emissions and coal consumption from a coal fire near Durango, CO; Inter. J. Coal Geol. 86 95-107.

Ide T S, Crook N and Orr Jr F M 2011 Magnetometer measurements to characterize a subsurface coal fire; Int. J. Coal Geol. 87 190-196.

Jenkins G M and Kawamura K 1976 Polymeric Carbons: Carbon Fibre, Glass and Char; Cambridge University Press, Cambridge, UK, 183p.

Kumar S, Pal S K, Vaish J and Shalivahan 2015 Utilization of magnetic gradient method for coal fire mapping of Chatabad Area, a part of Jharia Coalfield, India; Spec. Publ., J. Eng. Geol., pp. 170-176.

Khalil M H 2012 Magnetic, geo-electric, and groundwater and soil quality analysis over a landfill from a lead smelter, Cairo, Egypt; J. Appl. Geophys. 86 146-159.

Kuenzer C and Stracher G B 2011 Geomorphology of coal seam fires; Geomorphology 138(1) 209-222.

Li Y and Devriese S G R 2009 Enhancement of magnetic data by stable downward continuation for UXO applications; SEG Houston, pp. 1464-1468.

Li Y, Devriese S G R, Krahenbuhl R A and Davis K 2013 Enhancement of magnetic data by stable downward continuation for UXO application; IEEE Trans. Geosci. Rem. Sens. 51(6) 3605-3614.

Ma G, Liu C, Huang D and Li L 2013 A stable iterative downward continuation of potential field data; J. Appl. Geophys. 98 205-211.

Majumdar T J, Pal S K and Bhattacharya Amit K 2012 Generation of emissivity and land surface temperature maps using MODIS TIR data for lithological mapping over the Singhbhum-Orissa Craton, India; J. Geol. Soci. India $\mathbf{8 0}$ 685-699.

Mendonca C A and Silva B C 1993 A stable truncated series approximation of the reduction-to-the-pole operator; Geophysics 58 1084-1090.
Michalski S R 2004 The Jharia mine fire control technical assistance project: An analysis.; Int. J. Coal. Geol. 59 83-90.

Mishra R, Bahuguna P and Singh V 2011 Detection of coal mine fire in Jharia coal field using Landsat-7 ETM+ data; Int. J. Coal. Geol. 86 73-78.

Miller H G and Singh V 1994 Potential field tilt - a new concept for location of potential field sources; J. Appl. Geophys. 32 213-217.

Narayan S, Sahoo S D, Pal S K, Kumar U, Pathak V K, Majumdar T J and Chouhan A 2016 Delineation of structural features over a part of the Bay of Bengal using total and balanced horizontal derivative techniques; Geocarto Int. 32(1) 1-16.

Oruc B and Selim H H 2011 Interpretation of magnetic data in the Sinop area of Mid Black Sea, Turkey, using tilt derivative, Euler deconvolution, and discrete wavelet transform; J. Appl. Geophys. 74 194-204.

Pal S K and Majumdar T J 2015 Geological appraisal over the Singhbhum-Orissa Craton, India using GOCE, EIGEN6-C2 and in-situ gravity data; Int. J. Appl. Earth Obs. Geoinf. 35 96-119.

Pal S K, Vaish J, Kumar S and Bharti A K 2016a Coalfire mapping of East Basuria Colliery, Jharia coal field using vertical derivative technique of magnetic data; J. Earth Syst. Sci. 125(1) 165-178.

Pal S K, Narayan S, Majumdar T J and Kumar U 2016b Structural mapping over the $85^{\circ} \mathrm{E}$ ridge and surroundings using EIGEN6C4 High Resolution Global Combined Gravity Field Model: An integrated approach; Mar. Geophys. Res. 37 159-184, doi: 10.1007/s11001-016-9274-3.

Pal S K, Majumdar T J, Pathak V K, Satya Narayan, Ujjawal Kumar and Om Prakash Goswami 2016c Utilization of high resolution EGM2008 gravity data for geological exploration over the Singhbhum-Orissa Craton, India; Geocarto Int. 31(7) 783-802, doi: 10.1080/ 10106049.2015.1076064.

Pasteka R, Karcol R, Kusnirak D and Mojzes A 2012 REGCONT: A Matlab based program for stable downward continuation of geophysical potential fields using Tikhonov regularization; Comput. Geosci. 49 278289.

Prakash A, Saraf A K, Gupta R P and Sundaram R M 1995 Surface thermal anomalies associated with underground fires in Jharia coal mines, India; Int. J. Rem. Sens. 16 2105-2109.

Prakash A, Gupta R P and Saraf A K 1997 A Landsat TM based comparative study of surface and subsurface fire in the Jharia Coal Field, India; Int. J. Rem. Sens. 18(11) 2463-2469.

Prakash A and Gupta R P 1998 Land-use mapping and change detection in a coal mining area - a case study in the JCF, India; Int. J. Rem. Sens. 19 391-410.

Prakash A and Gupta R P 1999 Surface fires in JCF, India their distribution and estimation of area and temperature from TM data; Int. J. Rem. Sens. 20 1935-1946.

Revil A, Karaoulis M, Srivastava S and Byrdina S 2013 Thermoelectric self-potential and resistivity data localize the burning front of underground coal fires; Geophysics $\mathbf{7 8 ( 5 )}$ B259-B273. 
Revil A and Jardani A 2013 The Self-Potential Method: Theory and Applications in Environmental Geosciences; Cambridge University Press, 367p.

Rajaram M 2009 What's new in interpretation of magnetic data? Geohorizons, 50p

Salem A, Williams S, Fairhead J D, Smith R and Ravat D J 2008 Interpretation of magnetic data using tilt-angle derivatives; Geophysics 73 L1-L10.

Schaumann G, Siemon B and Yu C C 2008 Geophysical investigation of Wuda Coal Mining Area, Inner Mongolia: Electromagnetics and magnetics for coal fire detection; In: Spontaneous Coal Seam Fires: Mitigating a Global Disaster, UNESCO (ed.) Mera, International Research for Sustainable Control and Management, ERSEC Ecological Book Series, 4. Tsinghua University Press and Springer, Beijing, pp. 336-350.

Shao Z, Wang D, Wang Y and Zhong X 2014 Theory and application of magnetic and self-potential methods in the detection of the Heshituoluogai coal fire, China; J. Appl. Geophys. 104 64-74.

Singh B B, Srivardhan V, Pal S K, Kanagaraju S K, Kumar S and Vaish J 2015 Particle Swarm Optimization Inversion of Self Potential Anomaly for Detecting Coal Fires, a Case Study - Jharia Coal Field; Third Sustainable Earth and Sciences conference in Celle, Germany, EAGE, 13 October, doi: 10.3997/2214-4609.201414282.

Singh A K, Singh R V, Singh M P, Chandra H and Shukla N P 2007 Mine fire gas indices and their application to Indian underground coal mine fires; Int. J. Coal Geol. 69 192-204.

Singh K K K, Singh K B, Lokhande R D and Prakash A 2004 Multielectode resistivity imaging technique for the study of coal seam; J. Sci. Indust. Res. 63 927-930.

Srivardhan V, Pal S K, Vaish J, Kumar S, Bharti A K and Priyam P 2016 Particle swarm optimization inversion of self-potential data for depth estimation of coal fires over East Basuria colliery, Jharia coalfield, India; Environ. Earth Sci. 75(8) 688.

Stracher G B and Taylor T P 2004 Coal fires burning out of control around the world: Thermodynamic recipe for environmental catastrophe; Int. J. Coal Geol. 59 $7-17$.

Tripathi D D 2005 Prevention and Control of Coal Fires in Sealed-off Areas of Coal Mines Using Different Means of Inertization; In: Proc. Int. Conf. on Coal Fire Research, Beijing, China. pp. 179-181.

Vaish J and Pal S K 2013 Interpretation of Magnetic Anomaly data over East Basuria region using an Enhanced Local Wavenumber (ELW) Technique; 10th Biennial International Conference and Exposition on Petroleum Geophysics, Kochi, 23-25 November, p. 110.

Vaish J and Pal S K 2015a Subsurface coal fire mapping of East Basuria Colliery, Jharkhand; J. Geol. Soc. India 86(4) 438-444.

Vaish J and Pal S K 2015b Geological mapping of Jharia Coalfield, India using GRACE EGM2008 gravity data: A vertical derivative approach; Geocarto Int. 30(4) 388-401, doi: 10.1080/10106049.2014.905637.

Vaish J and Pal S K 2016 Subsurface coal fire mapping of Patherdih Colliery, a part of Jharia coal field, India; Geol. Soc. India Spec. Publ. 4 80-85, doi: 10.17491/cgsi/2016/ 95899.

Verduzco B, Fairhead, J D, Green C M and MacKenzie C 2004 The meter reader - new insights into magnetic derivatives for structural mapping; The Leading Edge $\mathbf{2 3}$ $116-119$.

World Bank Group 2003 Jharia Mine Fire Control Technical Assistance Project; Project ID INP010411, Borrower: Bharat Coking Coal Ltd., http://www4.worldbank.org/ sprojects/Project.asp?pid=P010411.

Xu S, Yang J, Yang C, Xiao P, Chen S and Guo Z 2007 The iteration method for downward continuation of a potential field from a horizontal plane; Geophys. Prospect. 55 883-889.

Zhang X M 1998 Coal fires in Northwest China - Detection, monitoring, and prediction using remote sensing data; Ph.D. dissertation, Int. Inst. Geo-Inform. Sci. Earth Observ. (ITC).

Zhang J, Wagner W, Prakash A, Mehl H and Voigt S 2004 Detecting coal fires using remote sensing techniques; Int. J. Rem. Sens. 25 3193-3220. 